\title{
Extrahepatic Bile Duct Lipoma
}

National Cancer Institute

\section{Source}

National Cancer Institute. Extrahepatic Bile Duct Lipoma. NCI Thesaurus. Code C5854.

A rare benign adipose tissue neoplasm of the extrahepatic bile duct. 